\title{
Acute toxicity study and phytochemical screening of selected herbal aqueous extract in broiler chickens.
}

\begin{abstract}
In order to collect ethnobotanical information about growth and health promoter plants as feed additive in broiler chickens, five medicinal plants Euphorbia hirta, Solanum torvum, Zingiber officinale, Curcuma longa and Zingiber zerumbet used by traditional medical practitioners for the treatment of several ailments of microbial and non-microbial origins were investigated for phytochemical screening and acute toxicity study. A total of 30 female broiler chicks were obtained. At 21 days of age, the chicks were allocated at random into six groups. Five chickens were assigned at random to each treatment in five replicates and kept in 30 cages (one chickens per cage) till five weeks of age. Five groups were administered a single oral dose of $2,000 \mathrm{mg} \mathrm{kg}-1$ b.wt. while $5 \mathrm{~mL}$ distilled water was given to the control group of birds as placebo. Phytochemical screening study showed that plant contained volatile oils, tannins, alkaloids, saponins, flavonoids. Alkaloids and steroids were only found in the aqueous extract of Euphorbia hirta. Tissues were harvested and processed for photomicrographic examinations. Macro and microscopic observations indicated no alteration in liver and kidneys of the treated birds with $2000 \mathrm{mg} \mathrm{kg}-1$ of selected herbal plants extract. In the hematological study, a highly significant decrease was observed in AST, ALT, ALP level of broiler group receiving the aqueous extract of E. hirta 14 after of administration. Acute toxicity study indicated that water suspensions of selected herbal aqueous extract are not toxic when administered by the oral route to experimental birds at $2000 \mathrm{mg} \mathrm{kg}-1 \mathrm{~b}$.wt. In conclusion, the results obtained in the present study are in agreement to a certain degree with the traditional uses of the plants estimated as prophylaxis against various diseases and promote of health.
\end{abstract}

Keyword: Antimicrobials; Boiler; Euphorbia hirta; Phytochemical; Toxicity. 